\title{
A simple design for a complex work domain - the role of sketches in the design of a Bachelor study's new folder structure for use by teachers, students and administrators
}

\author{
Torkil Clemmensen \\ Department of Informatics, Copenhagen Business School, \\ Howitzvej 60, DK-2000 Frederiksberg \\ Tc. inf@cbs.dk
}

\begin{abstract}
In this paper we explore the role of design sketches in Interaction design and work analysis in a case of designing a simple folder structure for elearning software used to do course administration at a higher education study programme. The case presents a detailed description of how developers use different work analyses to collectively reflect upon and interpret design sketches of possible support of different user groups' interaction within their complex work, learning and life contexts. We conclude with what was learned from the case make recommendations how to conceptualize the process of reading design sketches using work analysis.
\end{abstract}

\section{Introduction}

Design sketches contribute both to the outcome of design and development processes, as well as to a greater understanding of the work itself. For the development of a science of interaction design it is therefore crucial to understand the role of design sketches in the interaction design process. In this paper we explore the role of design sketches for interaction design and work analysis and then suggest an approach that we call an 'interpretative approach to reading design sketches.' An interpretative approach to design sketches within the framework of Interaction design may have three steps: 1) sketch(es) of interaction design and the empirical work analysis of human life and work contexts need to be outlined and presented, 2) the design sketch and the work analysis are connected through separate analysis, for example, an intertextual analysis that consists of comparing work analysis reports with design sketches, and 3) additional theory is used to reflect on the readings of the design sketch(es).

Empirical analysis of work within an interaction design framework may contain different analyses. First, analysis of the organizational usefulness of the future design may include analysis of meeting agendas and resumes, consultant reports, organizational content templates and policies, interviews with key individuals in the

Please use the following format when citing this chapter:

Clemmensen, T., 2006, in IFIP International Federation for Information Processing, Volume 221, Human Work Interaction Design: Designing for Human Work, ed. T. Clemmensen, Campos, P., Ongreen, R, Petjersen, Al., and Wong. W., (Boston: Springer), pp. 221-240. 
organization, and other methods [21, 22, 25]. Second, analysis of the individual usefulness of the future interaction design may include the creation of conceptual models, i.e., explicit ideas about how the future users should interact with the new design. Third, analysis of the different kind of work procedures that the new design will support may include task analysis. Fourth, analysis of how users in the future may use the new design can be envisioned in, for example, scenarios. Fifth, analysis of who the future users are may include the construction of personas, i.e., fictive users that are representative for a target group of users of the new design. Finally, the analysis of the user's mental interaction with the new design may include think aloud tests. In contrast to the many techniques available for work analysis, the design sketch technique itself does not receive any systematic treatment (see for example [7] or it is characterized as simple pen and paper drawings of icons, dialog boxes, etc. [21].

The connection of design sketches with work analysis may happen through separate analysis. We suggest an approach that relies heavily on end-user involvement through discussion groups when comparing the specific work analyses with the different design sketches. Such analyses may include comparison to organizational standards for such designs or semantic mapping analysis, such as: Are the words, concepts, etc, that are used in the design sketch taken from the work analysis? Does the design sketch convey the moods and feelings that the work analysis suggested? Does the design sketch illustrate how a task is supported? It may also include analysis of how the design as sketched should be maintained and how it will be compared to competitors' choices of similar designs. Many other analyses are possible. What may be critical, however, is going beyond the textbook approach of interaction design to sketches ${ }^{9}$ in order to develop a set of separate user-oriented analyses that connects work analysis and sketching.

Reflecting on the readings of the design sketch(es) involves the use of additional theory beyond Interaction Design Theory. First of all, the theory behind empirical work analysis, for example [16, 22, 25], and behind 'cognition in the wild' [14] is relevant to understanding what work analysis is and how to develop how work analysis can be used to say something about the design sketch. Second, we need the theory of design sketching $[10,19,20,27]$ to appreciate what the design sketch contributes to interaction design, including theory about how we by reading the design sketches also learn more about the work analysis.

${ }^{9}$ The interaction design textbook of Preece, J., Rogers, Y. and Sharp, H. Interaction Design: Beyond Human-Computer Interaction. John Wiley \& Sons, 2002. has one entry on sketches. This entry discusses the designer's anxiety related to showing his or her inadequate drawing skills. 
The rest of the paper explores the interpretative approach to reading design sketches by analysis and discussion of a case of the development of a new Bachelor's study folder structure for use by teachers, students and administrators;

Figure 1 illustrates the new folder structure at the end of the case period. (The figure is in Danish. Each entry in the folder structure represents a student class).

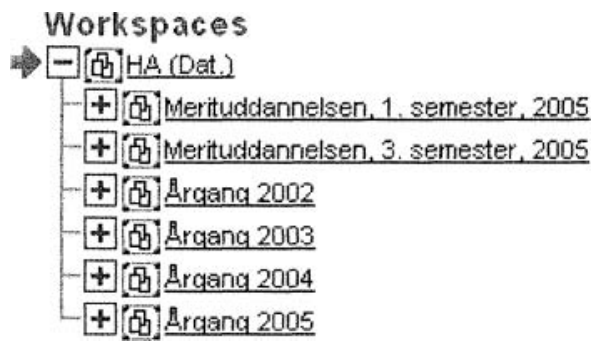

Figure 1. A simple design for a complex work domain: The folder structure of a Bachelor's study programme.

We first provide some background for our approach to reading design sketches. Second, the research methodology is outlined as an 'action research' oriented case study. Third, we present the case and analyze: how the developer group approached work analysis through organizational analysis, task analysis, scenario development and usability testing; how these analyses were applied in the discussions and interpretation of sketches and prototypes that were designed and used during the development of the folder structure; and how the developer group's use of design sketches reflected possibilities for supporting different user groups' interaction within their various work, learning and life contexts. We conclude with lessons learned from the case, and recommend how to conceptualize the process of reading design sketches.

\subsection{Background: design sketching and work analysis}

Interaction design is presented in textbooks as an approach consisting of conceptual models, scenarios, HTA task analysis, persona, think-aloud evaluation and other user centered techniques $[7,21]$. These techniques may be seen by more engineering oriented designers as 'work analysis' techniques and not directly related to design [5]. However, textbook interaction design also includes prototypes, storyboards, 
sketches, etc. Sketches, i.e., freehand drawings or low fidelity prototypes, have been studied by researchers for their role in design and have been found to stimulate reflection, particularly in the early stages of design [20].

When going from analysis to design, from conceptual models to physical design, interaction design relies heavily on iterative testing of prototypes with users of the future product [21]. A large number of techniques for user requirement elicitation and user tests are available for use in interaction design $[16,21,25]$. In many of these techniques, communication between stakeholders about user requirements is supported by the use of prototypes, mock-ups, etc. However, not much is said about the use of freehand drawing sketches (sometimes called low fidelity prototypes) when going from analysis to design. For example, it is not well defined how to use organizational analysis, task analysis or scenarios in combination with one or more design sketches.

Having a focus on how to use work analysis to read design sketches is a different approach from design cognition that asks questions such as: "Do abilities of the designer, like general intelligence, visual abilities regarding imagery and perception, and creativity, influence the usefulness and quality of sketching?' $[1,11]$. The focus is also different from research in artifical intelligence support to design, which tries to build computational tools for design evaluation that may present critiques in the forms of text, diagrammatic annotation and 3D model to the designers' sketches [19]. It is also different from studies of design practice that may try to describe how designers during design imagine their users [13]. Using work analysis to read design sketches is a different approach from the approach used in studies of how to use ethnographic field methods in participatory design [12], though it can be seen to be closely related $[2,23]$. Instead, we see the use of work analysis to read design sketches as an interpretative approach.

\section{Research methodology}

In the sections below we present a case study [8]. of the development of a new Bachelor's study folder structure for use by teachers, students and administrators in a Computer Science and Business Administration programme. This development process is studied within a one year period at the researcher's own university (Copenhagen Business School ${ }^{10}$ ). The sources of information included background reports, emails and notes from meetings, videos of test situations and, in particular, design sketches from the development group. Further, the author of this paper played a central role as chair or the developer group in the case. The context of the case was a decision taken by the university's top management that ordered the study board to

${ }^{10}$ Copenhagen Business School has around 14,000 students and an annual intake of around 1,000 exchange students. With this number of students as well as around 400 full-time researchers and around 500 administrative employees, CBS is the one of the 3 largest business schools in Northern Europe. 
stop using their own in-house developed course administration system and begin using the university's standard course administration system. From this followed the need for designing the folder structure of the new system's in a way that accommodated and in some cases changed the course administration process known to the users of the old system.

This case illustrates an interpretative approach to reading design sketches using work analyses as input. The analysis of the data is focused on the use of design sketches. We provide a description of different types of work analysis done by the developer group, how these analyses were used in the discussions of the sketches, and how the sketches were annotated and interpreted and reflected upon during the process. We unfold the context of the case by presenting a chronology of meetings in the developer group with a particular focus on the meetings in which design sketches played the major role. Finally, we report on the lessons learned from the case study.

\section{Case Study Analysis and Results}

In October 2004 the members of the study board received an email saying:

"The deans and the university administration have decided that the platform Sitescape now is mandatory for all courses and all students at the university. Therefore you at your study program have to begin using this platform no later than autumn semester 2005."

The email marked the end of a year-long political discussion in the study board of the value of retaining the old in-house developed course administration system called DIVE at the study programme. It was also the beginning of the transition from the old to the new system that is described in this case. The analysis and the results of the case study are presented below.

\subsection{The work analysis}

The study board's response to the direct order from the head of the university to abandon DIVE in favor of the university's current standard system called Sitescape was to appoint a developer group. The developer group had as its goal to make the transition from the old system to the new system bearable and workable for all user groups. It consisted of representatives from teachers, study administration, students and experts from the university learning lab, with the author of this paper as the chairman. This developer group began its work half a year before the new system had to start working and finished seven months after that date, i.e., the period during which the developer group functioned was a little more than a year. During that period the developer group held a number of meetings (see Table 5 below) to analyze the course administration work performed by different user groups and to develop the new folder structure. The work analyses are described in the following sections. 


\section{Organizational analysis}

The organizational analysis of the course administration process and the old system was done by the developer group on the basis of archival data and knowledge from within the group. A consultant report of needs and requirements for a new system had been authored by a former student at the study programme. This student had worked extensively on this topic during his studies, had been a member of the previous as well as the current study board, and was seen as one with some insight into the work procedures surrounding the course administration. The consultant report on course administration had three main points: 1) the need for one-way communication from the study administration to the students and teachers, 2) a continuous need for re-organizing the structure of the material used in courses (for example, teachers needed to establish new shared locations for material to all students as new topics were introduced in teaching), and 3) the need for a 'branding' of the study through design of the system, both internally towards students, teachers and secretariat, and externally towards potential applications for the study. Furthermore, the developer group became aware of the existence of a content template for 'study-zones' (?the folder structures system of the new system) authored by experts from the university's learning lab and authorized by the central study administration at the university. This template made it clear that the developer group should leave out tasks related to study administration and focus on the tasks related to course administration.

\section{Task analysis}

The task analysis of the course administration work was done as two different analyses. Two sub-developer-groups, a student and a teacher/administration group, did each a task analysis. As seen in Figure 2 and Figure 3, the student group did it as a 'use case' analysis [17]. This task analysis was confirmed by a task analysis done by another student group that also showed that checking for new teaching material and sharing documents in relation to teaching were two main tasks of course administration for students.

Use Case: Find teaching material
1. Find year
2. Find subject
3. Find module
4. Find teaching plan
5. Find teaching session 
Figure 2. Student sub-developer-group's task analysis of 'find teaching material'

Use Case: Knowledge sharing in a student group

1. Establish group

a. Find group members

2. Install permissions

3. Agree on rules for cooperation

4. Make structures within the student workgroup

5. Upload documents

Figure 3. Student sub-developer-group's task analysis of 'knowledge sharing in a student group'

The teacher sub group did a task analysis that showed that upload and sharing of documents was the most frequently performed task by teachers. Typically, they had to upload their presentation slides to make them available to students. Apart from uploading of slides, teaching plans, assignments, etc., no other task was required of teachers in relation to course administration. However, the teachers' tasks were not independent of the pedagogical strategy that was used in the study programme; many teachers reported informally of the experiences with managing discussions, online supervision of assignment work and other interactive tasks. Furthermore, the task analysis showed that the setting up of new system users was a task that required getting access to other systems at the university, selecting users, naming groups, and more, and therefore was a task that should be done mainly by the study administrators. Teachers were also responsible for archiving data, i.e., establishing the memory of the study programme.

\section{Scenarios and personas}

On the basis of the use cases, the developer group developed several scenarios [3] with associated personas [18]. In one scenario, Hjalte and Christian were two bachelor students who wanted to establish a study group, to share documents and to find material from the teacher. In another scenario Peter, a senior teacher with a lot of experience, wanted to set up a forum for his teaching, upload a large number of files, and monitor the changes, for example, if students had commented or asked questions regarding the material uploaded by the teacher. Pther kinds of scenarios were important too; for example, one of the experts from the university's learning lab presented four generic scenarios that illustrated different visions of how to teach with the support of the system: lecturing, class teaching/preparation, class teaching/problem solving and team assignment/project. Taken together, these scenarios with their included personas suggested ideal future users and ideal future situations of use of the new Sitescape system in course administration. These scenarios were presented at an appropriate time (at a meeting in August) for all teachers and students at the study programme. 


\section{DEVELOPER GROUP MEETINGS \\ January 2005}

Establishing goals (design of folder structures) and resources (limited to workgroup)

February

Organizational analysis and task analysis: Establishing user subgroups: students, administration, teachers. Presenting expertise from central unit and experience from other study-programmes. Distributing consultant reports on old

versus new system and manuals and papers about the new system. Giving workgroup members access to new system

March

Sketches from user subgroups (student, teacher/administrator)

April 2005

Hi-fi prototypes from expert designer

May 2005

Folder structures implemented on new system June 2005

Scenarios and Think aloud tests of implemented folder structure

August 2005

Involving all teachers and students in analysis of the use of the new system as a pedagogical tool

September-December

New system is operative.

January 2006

Evaluation of the first semester with the new system

The old sustem information estahlished as an archive at new svstem

\subsection{Using the work analysis}

At the same time that the developer group indulged in the above presented work analysis activities, the developer group came up with several design sketches in the form of low fidelity prototypes. Sketches illustrating the points and arguments of the sub developer group were presented at meetings in the developer group (see Table 5 for a list of the meetings in the developer group). These meetings took place between the large meetings. During the meetings the sketches were annotated with points taken from discussions in the group. In this way, the sketches were connected to the work analyses through discussions in the developer group and used as input for the next round of analysis and sketching. The annotated design sketches are presented below. 
Table 5. Meetings in the DIVE (old system) - Sitescape (new system) developer group

\subsection{The design sketches}

During the developer group's period of existence, several design sketches in the form of low fidelity prototypes were made. Each sub-developer-group provided sketches illustrating the points and arguments of the group. The student sub-developer-group did two sketches: one of the principles of organizing the folder structure and one illustrating an example of an unfolded structure.

The students' sketch of the principle folder structure that was created is shown in Figure 4; the annotations on the the left side of the figure relate to the classes, those in the middle refer to the courses, and those on the right comment on the student groups; the row at the bottom of the figure explains the symbols used in the figure. The students presented their sketch as a 'long-life', transparent and easy-to-use folder structure for students as well as teachers. They argued for a structure with two levels and a third level consisting of folders only. They requested that the third level (the right-most column in

Figure 4) be tailored to each individual course.

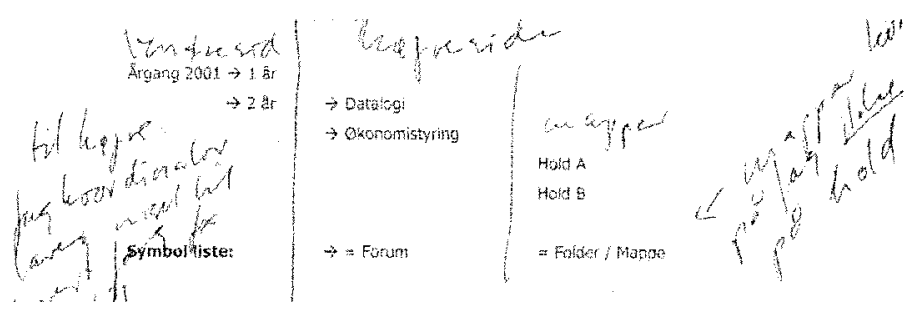

Figure 4. The students' sketch of the principle in the new folder structure

The annotations on the principle sketch in

Figure 4 also reflect the developer group's discussion that showed the students wanting their teachers to be primarily responsible for tailoring the structure on the lower levels to the need of the students. A translation of the annotation on the left is: "The course coordinator makes some information for each course...", which suggests that the students wanted the coordinator to take responsibility for the content. The annotation on the right says: "folders should be on courses, not on student groups" which again moved the responsibility for the information from the student group to the teachers. This built-in division of work between students and teachers was made even clearer by the sketch produced by one of the students of the unfolded structure (see

Figure 5). 


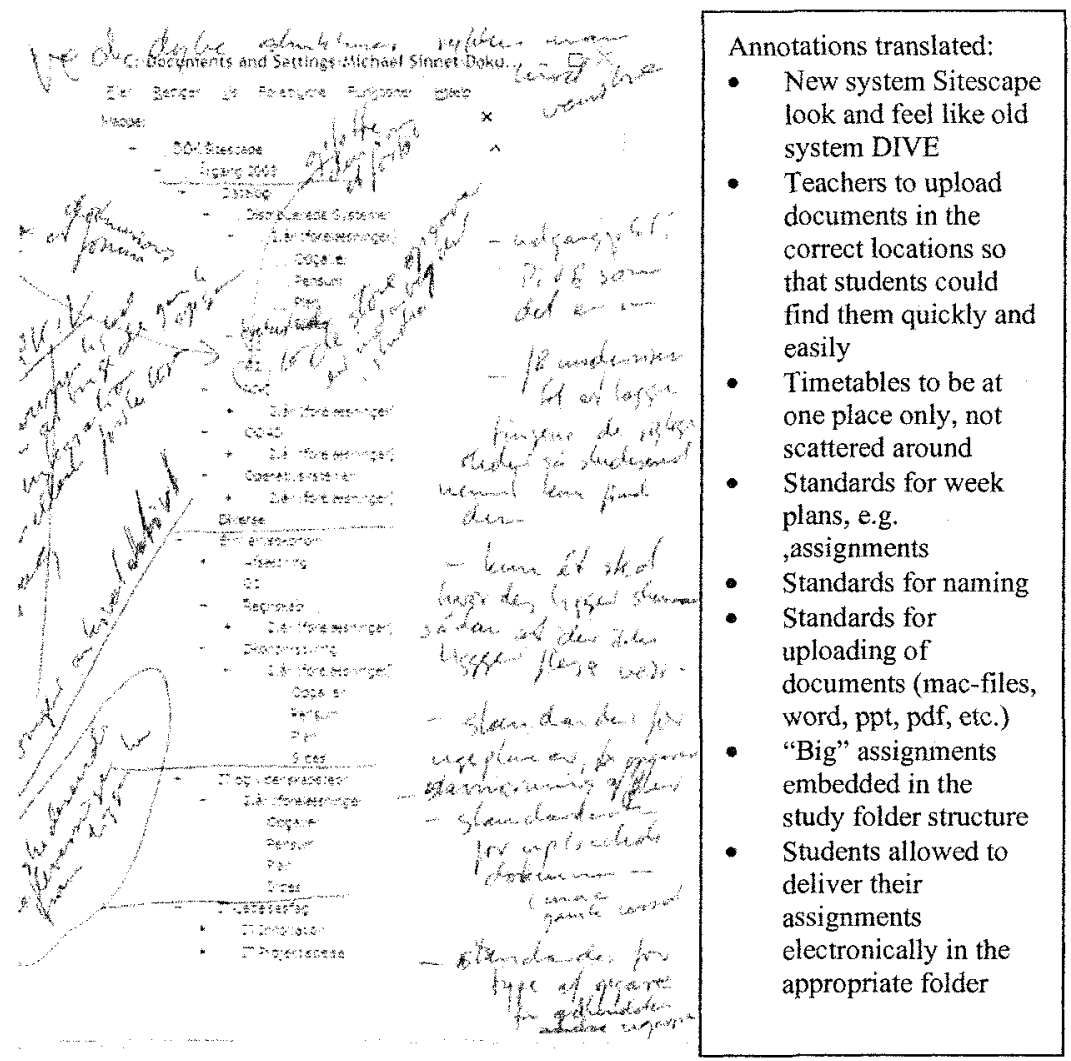

Figure 5. The students' sketch of the unfolded structure

The students' sketch of the unfolded structure in

Figure 5 shows a deep unfolded structure with each student class at the highest level, the courses at second level, and inside these, the folders for each course. Although the figure is in Danish, the handwritten annotations from the meeting discussion of the sketch are translated into English. From the annotations it is clear that several points were not explicitly stated by the students but had to be elicited during group discussion (as seen on the right part of

Figure 5). As these points illustrate, the students wanted the teachers to think seriously about improving their use of the folder structure; e.g., teachers should obey standards for naming, document format, ete.

The left side of the teacher sub-developer-group's sketch of the folder structure in Figure 6 shows the structure for each semester, the right side of the sketch folders referring to lectures, notes, messages and exercises classes, and the right bottom relating to general information. 


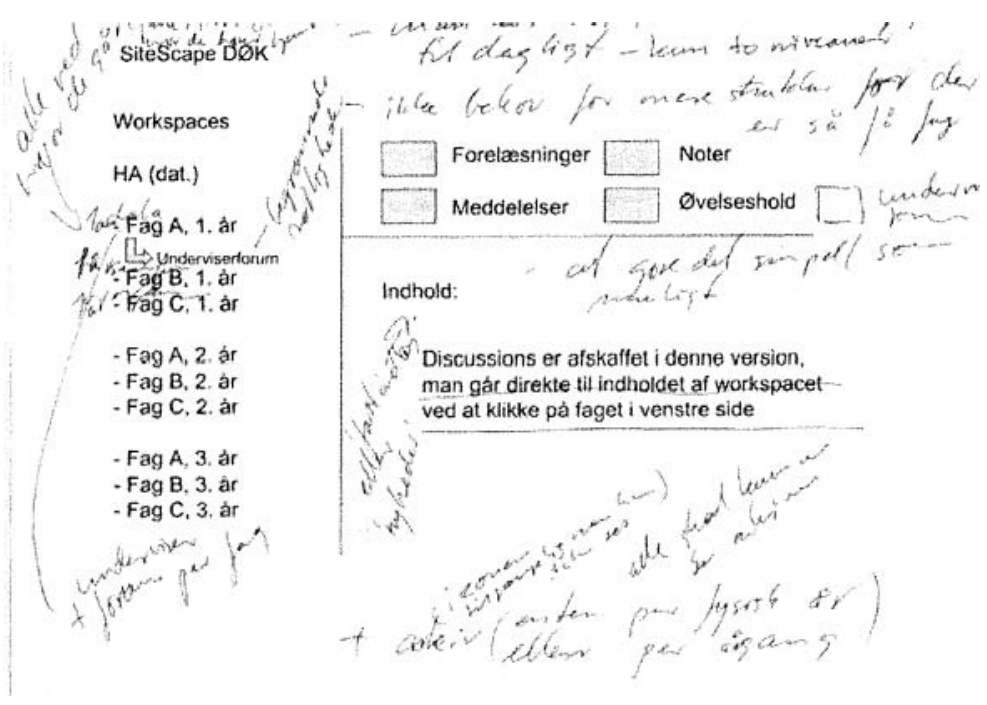

Figure 6. The administration/teacher sub-developer-group's sketch.

The written annotations on the sketch (in Danish) reflect the outcome of the developer group discussions of the teachers' sketch: a) for daily teacher use there is only a need for two levels of structure since there are so few courses, b) the teachers want it to be as simple as possible due to their heavy workload often being distributed across several studies, and c) an additional forum for teachers only should be added to the structure. Furthermore, the developer group considered the sketch in its content organization and layout - as much dominated by the IT support individual. She had a clear grasp of how the new system appeared in several of the other study programmes at the university and wanted something similar. She wrote in an email:

...in my opinion it has no relevance to develop a whole new proposal for a zone construction [the folder structure], I rather think it pays of to look at this cand.merc. zone [a competing study programme's folder structure] ...then it must be up to those who make the final solution to take into account all requirements..."

It came out strongly from the presentation and discussion of the administrator/teachers sub-developer-group's design sketch that the teacher representatives, together with the study administration representatives, saw a need for a simple structure that complied with organizational standards. This was because teachers and administrators had to work on several study programmes and did not want to specify interfaces for any of these study programmes.

The sub-developer-groups' sketches, i.e., the students' and the teachers' design sketches, and the discussion of these in the developer group led the developer group to conclude that the learning lab expert should develop new high-fidelity prototypes illustrating what different solutions would look like in the real system. 


\section{The expert's sketches}

The high-fidelity prototypes developed by the learning lab expert illustrated different solutions, i.e., a hierarchical folder structure vs. a flat folder structure. A flat hierarchical combined prototype was also produced, but did not make any impact in the working group and will not be presented here.

The prototypes presented in Figure 7 and Figure 8 had similar top level structures (a teacher forum and a student forum at the top, and student developer groups at the bottom), but different lower level structures (hierarchical vs. flat). The prototypes were implemented in the existing Sitescape system as dummy pages with access codes only to developer group members, in order to illustrate how the folder structure would appear on the screen, including font, text organizing, pictures, links, and integration of other web sites.

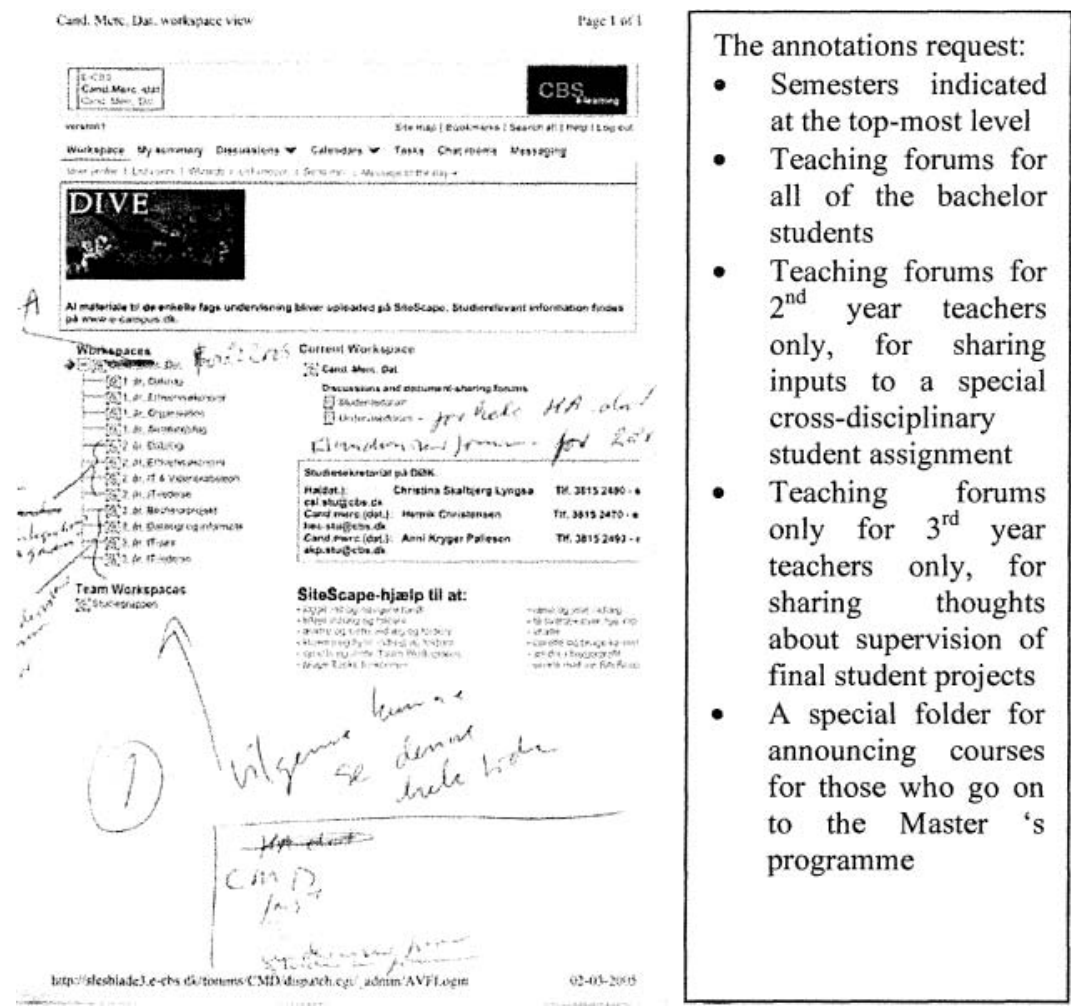

Figure 7. Prototype 1. The expert's sketch of a flat folder structure

The group discussion of the prototypes focused on advantages and disadvantages of each prototype; each participant in the developer group was required to access the prototypes and test the prototype for three bad things and three good things, and be ready to report these at the meeting in May (see Table 5). 
In the high fidelity prototype 1 (see Figure 7 which is in Danish with translations at the right) the expert designer illustrated one version of a flat folder structure, with all the courses listed at the highest level. The expert designer's arguments for prototype 1, apart from the flat structure in itself, were that advantages included fewer clicks, only current courses on the screen, and the possibility for several discussions under each course. The disadvantages which the expert perceived were that it would take more work to archive data after each semester and that the user had to go to another place in order to find both old courses from the current year and material from the previous years.

However, the expert designer of the high fidelity prototype 1 had mixed the Master's programme with the Bachelor's programme, evident from the attempt to correct the wrong study programme name in the annotations made during group discussion (marked ' $A$ ' in Figure 7). Also, the annotations on the expert's sketch reflect how during discussion of the sketch the group became aware of the need for several forums for teachers, not only one.

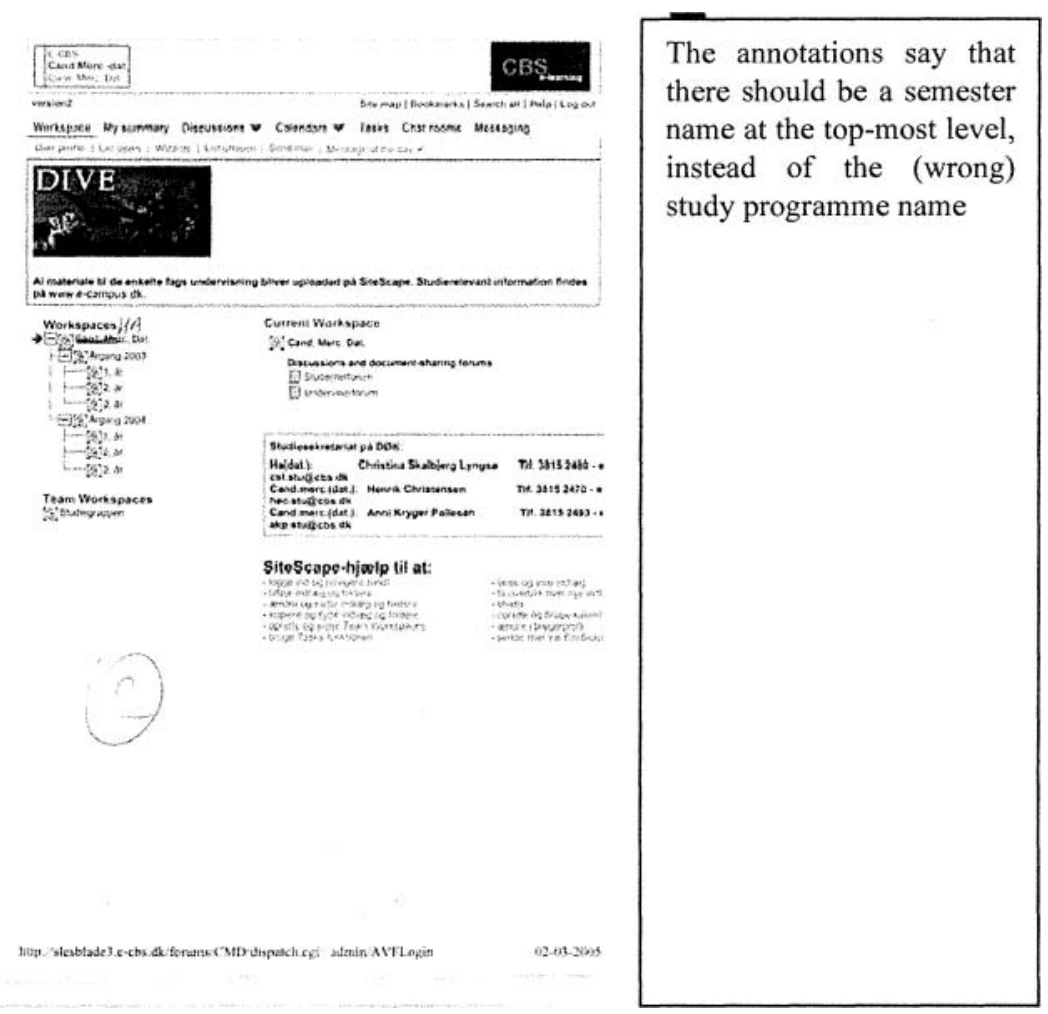

Figure 8. Prototype 2. The expert's sketch of a hierarchical folder structure. 
In the high fidelity prototype 2 (see Figure 8) the expert designer illustrated a hierarchical folder structure that was an exact copy of the old DIVE system folder structure. The expert designer's arguments for the advantages of prototype 2 included that it was easy to go the courses from one's own class, and in general other classes were easily accessible; the disadvantages included too many clicks, a deep structure, folders within folders made it harder to attain an overview than folders in Discussions (a standard folder given by the system). Additionally, the teacher forum needed to be outside courses and not within courses (due to a folders inheriting access rights form Discussions standard folder). As the lack of annotations in prototype 2 reflects, the developer group did accept these arguments without further discussion.

At the May meeting (see table 1) the group chose between the prototypes and recommended version 2 to the study board on the basis of its resemblance to the old system and the good features that were attributed to the overview and accessibility.

\section{Evaluation of the prototype}

A think aloud testing of the chosen prototype 2 was done using scenarios as scripts for role play. Representatives from each user group (students and teachers 1 1 , see Figure 9 and

Figure 10) were asked to describe a typical scenario and then to perform this scenario within the new system while thinking aloud. This was recorded on videos, which were then searched for usability problems and benefits.

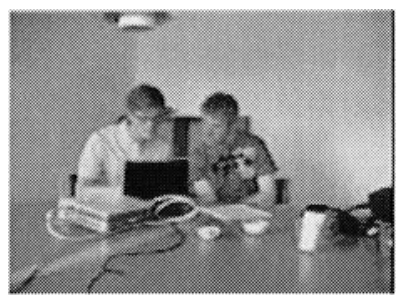

Figure 9. The students doing think aloud test of prototype 2.

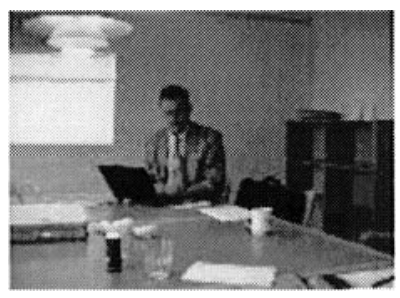

${ }^{11}$ The user groups that did think aloud testing did not include the administrators, because they had already at a special meeting in June got supervision from the learning lab expert to use the system to do their task of registering new courses. 
Figure 10. The teachers doing think aloud test of prototype 2.

The results of the think aloud tests were contradictory; on the one hand, the system including the new folder structure was ineffective and unsatisfactory to both students and teachers; one the other hand, the folder structure seemed easy to learn and easy to re-learn, quite secure and also compatible with other study programmes' use of the system. In other words, the think aloud tests in both test user groups showed mixed benefits for students' and teachers' use of the new system.

At a later occasion (in August) the think aloud videos were shown at an open meeting for all those associated with the study programme. This audience of teachers and study board members and experts from the university's learning lab expressed general satisfaction with the new system, confirming that the system was easy to learn to use. However, a consultant with e-learning expertise, who had experience of the system from other study programmes at the university, but now saw saw prototype 2 for the first time, clearly indicated that the developer group had made the wrong choice, that is, they should have chosen prototype 1, which other study programme had done. This left the question of the quality of the new folder structure somewhat open for a time.

\section{After implementation evaluation}

Prototype 2 was actually implemented as the study programme's new course administration system, as seen in

Figure 11. After having operated the new system for a whole semester, the developer group at a meeting (in December) planned the evaluation of the folder structure and discussed feedback from different user groups. As chair of the developer group, this researcher sometimes received emails from teachers. For example, a cc was received of one teacher writing to another teacher:

"I can see you have uploaded some eclipse.jar, but I still cant se what it is,

because I still don't have access to the teacher forum on $1^{\text {st }}$ year!"

Another teacher wrote to this researcher directly:

"I have been fully satisfied with Sitescape which I have only used as a place for uploading documents to the students."

It appeared that those of us in the developer group had received only part of the story - not the full story from all perspectives - of the transition from the old to the new system with a new folder structure for use by teachers, students and administrators. 


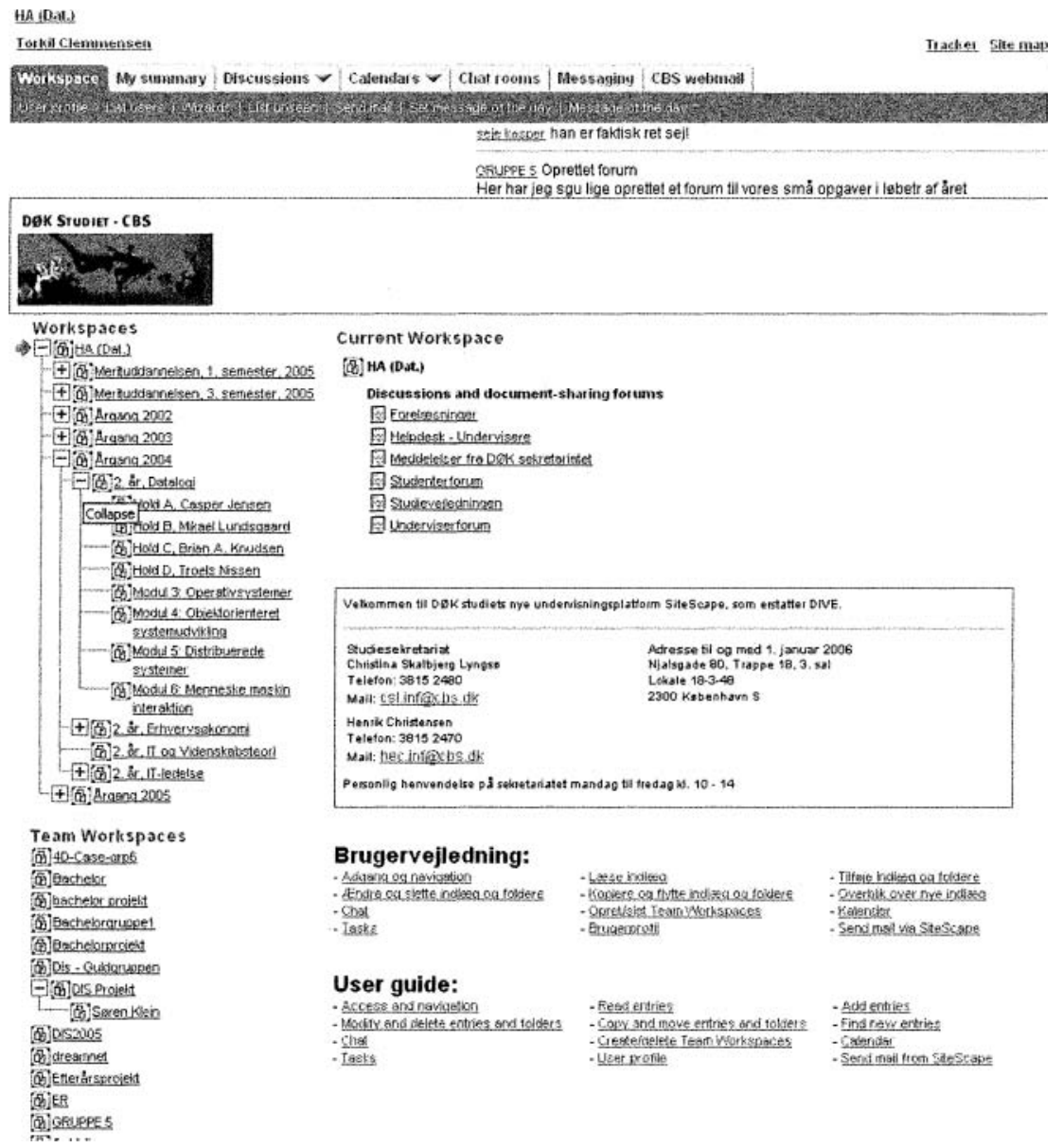

Figure 11. The implemented version of prototype 2 folder structure.

\section{Discussion}

The case described above of moving from an old to a new system for course administration illustrates how interpretative processes are at play on several levels of the organization in order to connect work analysis and design sketches.

\section{Design sketches are tools in work analysis}

One lesson learned from the case was that the collective discussion of the design sketches revealed much about the course administration work itself. From a work analysis perspective, a theoretical framework that may illuminate understanding of 
the use of design sketches in the case presented here is distributed cognition, a theory that purports that both individual and collective cognition can be and generally is distributed across time and space $[6,14]$, for example, in a flight cockpit [15] or in a courtroom or a medical practice [9]. Having this focus makes it interesting to analyze how information is propagated across different representations during a specific period of time. In this perspective, information about how to do course administration was propagated across the developer group's design sketches. The design sketches were used as working memory registers that enabled the group to share the immediate thoughts. However, it is not always easy for everybody to share immediate thoughts; thus, this process had to be supported by formal think aloud testing of the prototypes. The developer groups' collective use of the design sketches as memory registers also made the design thinking more robust and relevant than if one member of the developer group sequentially stated his or her requirements of the new design. In this way, the developer group became part of the course administration in a time of difficulties - at one occasion it wasn't clear whether the developer group did course administration or development of course administration. The lesson learned from the case is that within a distributed cognition perspective, design sketches are tools in the ordinary human activity that the development activities support? (in this case the course administration). This means that a design sketch could be evaluated not as the outcome of work analysis but as a contribution to work analysis.

\section{Design Sketch Ownership}

One obvious critique of the research presented here is that the sketches that are analyzed above are not really design sketches, but are PowerPoint low fidelity prototypes or the equivalent. According to the dominant view of design sketches (Orngreen, this issue), a design sketch is a hand drawing that conceptualizes an idea and which has not been taken too far towards something that can be presented and perceived as a solution. In contrast to this view, the case study presented here illustrates that solution spaces can and will be explored by the use of any kind of drawing including power-point low fidelity prototypes and other computer drawings by end-users and other stakeholders. Somebody owns the design sketch, that is, each sketch is an expression of someone's perspectives and feelings towards the work to be supported. From a design sketch perspective, the use of different representations, sketches, low and high fidelity prototypes for communicating with other people and hearing their views. In particular, the use of sketches with annotations of what is good, bad and how they meet requirements is recommended by practitioners ${ }^{12}$.

In the case presented here, the use of different representations, sketches, low and high fidelity prototypes was necessary to address the various levels of organizational learning about (and at the same time performing) the teaching and study administration using the new folder structure raised by the organizational analysis initiated at the beginning of the developer groups meetings. Each user group needed at least one sketch, as reflected in different sketches from the students and the

${ }^{12}$ See e.g. http://www.kurtz.ws/teaching/1542-v2/assgn.htm, retrieved Monday, December 19, 2005 or http://www.sapdesignguild.org/editions/edition1/miniapp_design.asp, retrieved Monday, December 19, 2005. 
teachers. Furthermore, each institution needed separate sketches of the new structure. The university's learning lab expert provided prototypes that were based on the sketches and ideas discussed in the developer group but which clearly twisted the ideas in new directions. This cognitive and social answer to the use of sketches is different from the creativity enhancing role that current theory of design sketching identifies $[10,19,20,27]$. It seems its focus is on who presents the sketch more than an understanding of design sketches as cultural and emotional carriers. [26].

\section{The design sketch as mediating artifact}

It appears from the case that analyzing work is one process, drawing design sketches is another, and connecting the sketch and work analysis is a third process. The connection of design sketches with work analysis may thus be understood as an entirely separate analysis (in addition to work analysis and design sketching), for example as a form of analogical reasoning about novel design concepts, or as a kind of intertextual analysis of design sketches and work analysis reports.

In analogical reasoning about novel design concepts, it is worthwhile recognizing that there is a difference between design sketches (including low fidelity prototypes) and high fidelity prototypes: It may be easier to explain design concepts by use of design sketches than by use of high fidelity prototypes, $\backslash$ because design sketches facilitate analogies between domains, while high fidelity prototypes (examplars) facilitate reasoning within domains [4]. Thus, in our case example design sketches may facilitate analogical reasoning between the old system and the new system.

In an intertextual analysis, the role of the developer group meetings in the reading of design sketches may be that of providing collective interpretations of the sketches by inclusion of end-users, a process whereby the complexity of the design becomes apparent. In other words, what is designed is both the artifact (the folder structure), the work procedures (the interaction with the folder structure) and the human beings (what is means to be a student, teacher and administrator) - a perspective that in recent years has been made popular in information system research as actor network theory [24]. In this case, the lesson learned through the intertextual perspective is that work analysis results are compared with design sketches, i.e., evaluating sketches (with or without end-users of the new design being present) includes comparison to organizational standards for such designs, to task analysis, to scenarios and to other forms of texts. It may also include analysis of how the design as sketched should be maintained and how it could be compared to a competing design choices.

\section{Conclusion}

The interpretative approach to understanding the role of design sketches in interaction design and work analysis which is presented in this paper suggests that the interpretations take place during meetings by oral commenting and by written annotations on the sketches. The comments and annotations, i.e., the interpretations, may be understood as a kind of intertextual analysis that compares and connects work analysis reports and design sketches. Furthermore, the presented case makes it 
clear that many sketches are needed for even a simple design when the work domain is complex.

\section{Acknowledgement}

Gratitude is shown to the anonymous members of the working group at the study programme for their enthusiastic input and the design suggestions made during the one year period. The case study was made possible due to support by the head of the study board, Jacob Nørbjerg. Appreciation is also due to Karl Kautz, Dept. of Informatics, CBS for commenting upon early drafts of this paper.

\section{References}

1. Akin, Ö. Variants in Design Cognition. in Eastman, C., Newstetter, W. and McCracken, M. eds. DESIGN KNOWING AND LEARNING: COGNITION IN DESIGN EDUCATION, Elsevier, 2001, 301.

2. Blomberg, J., Suchman, L. and Trigg, R.H. Reflections on a Work-Oriented Design Project. Human-Computer Interaction, 11 (3). 237-265.

3. Carroll, J.M. Five reasons for scenario-based design. Interacting with Computers, $13(1)$. 43-60.

4. Christensen, B.T. and Schunn, C.D. The relationship between analogical distance to analogical function and pre-inventive structure: The case of engineering design. Memory \& Cognition.

5. Clemmensen, T. and Nørbjerg, J. Separation in Theory - Coordination in Practice. Software Process Improvement and Practice, 8. 99-110.

6. Cole, M. and Engestrøm, Y. A cultural-historical approach to distributed cognition. in Salomon, G. ed. Distributed cognitions - Psychological and educational considerations, Cambridge University Press, 1993.

7. Cooper, A. and Reimann, R.M. About Face 2.0: The Essentials of Interaction Design. Wiley, 2003.

8. Creswell, J.W. Qualitative inquiry and research design - choosing among five traditions. SAGE, London, 1998.

9. Engestrøm, Y. Interactive expertise - Studies in distributed working intelligence. Research Bulletin, University of Helsinki, Department of Education, 83.

10. Fallman, D., Why Research-oriented Design Isn't Design-oriented Research. in Nordes: Nordic Design Research Conference, (Copenhagen, Denmark, (2005)).

11. Hamel, R., Psychology and Design Research. in Design Research in the Netherlands, (1995).

12. Harper, R.H.R. The Organisation in Ethnography- A Discussion of Ethnographic Fieldwork Programs in CSCW. Computer Supported Cooperative Work, 9. 239-264. 
13. Hasdogan, $\mathrm{G}$. The role of user models in product design for assessment of user needs. Design Studies, 17. 19-33.

14. Hutchins, E. Cognition in the wild. MIT Press, 1995.

15. Hutchins, E. How a Cockpit Remembers Its Speeds. Cognitive Science, 19 (3). 265-288.

16. Kirwan, B. and Ainsworth, L.K. (eds.). A guide to task analysis. Taylor \& Francis, 1992.

17. Mathiassen, L., Munk-Madsen, A., Nielsen, P.A. and Stage, J. Object Oriented Analysis and Design. Marko, Aalborg, 2000.

18. Nielsen, L., From user to character. in Designing Interactive Systems, (London, 2002).

19. Oh, Y., Gross, M.D. and Do, E.Y.-L., Critiquing Freehand Sketching - A Computational Tool for Design Evaluation. in Visual and Spatial Reasoning in Design [VR'04], (MIT, Cambridge, USA, 2004).

20. Oh, Y, Yi-Luen Do, E. and Gross, M.D., Intelligent Critiquing of Design Sketches. in AAAI Fall Symposium - Making Pen-Based Interaction Intelligent and Natural, (2004).

21. Preece, J., Rogers, Y. and Sharp, H. Interaction Design: Beyond HumanComputer Interaction. John Wiley \& Sons, 2002.

22. Rasmussen, J, Pejtersen, A.M. and Schmidt, K. Taxonomy for Cognitive Work analysis, Risø National Laboratory, 1990.

23. Siegel, D. and Dray, S. Avoiding the next schism: etnography and usability. Interactions, march + april 2005.

24. Tatnall, A. and Gilding, A., Actor-Network Theory and Information Systems Research. in 10th Australasian Conference on Information Systems, 1999, (1999).

25. Wilson, J.R. and Corlett, E.N. (eds.). Evaluation of human work - a practical ergonomics methodology. Taylor \& Francis, London, 1992.

26. Yammiyavar, P.G. Emotion as a semantic construct in product design, IIS, Bangalore, 1999, 367.

27. Yi-Luen Do, E., Gross, M.D. and Zimring, C., Drawing and Design Intentions -- An Investigation of Freehand Drawing Conventions in Design. in Design Thinking Research Symposium, (Cambridge MA, 1999). 